\title{
Electrochemical Dilatometry Study on Si-Embedded Carbon Nanotube Powder Electrodes
}

\author{
Sangjin Park, Taeahn Kim, and Seung M. $\mathrm{Oh}^{*, z}$ \\ Department of Chemical and Biological Engineering, and Research Center for Energy Conversion and
} Storage, Seoul National University, Seoul 151-744, South Korea

\begin{abstract}
Si-embedded carbon nanotube ( $\mathrm{Si}-\mathrm{C} / \mathrm{NT})$ powders were prepared by dispersing carbon nanotubes (CNTs) and Si in the tetrahydrofuran solution containing poly(vinyl chloride) (PVC) as a dispersion agent, and then carbonizing the PVC. A better cycle performance was observed with the $\mathrm{Si}-\mathrm{C} / \mathrm{NT}$ containing larger void volume. The origin of this feature was addressed by an electrochemical dilatometry study, where it was found that the electrode swelling becomes less significant when the Si-C/NT possesses a larger void space. It is believed that the void space plays a buffering role against the volume expansion of $\mathrm{Si}$, alleviating the breakdown of electrode integrity.

(C) 2007 The Electrochemical Society. [DOI: 10.1149/1.2717365] All rights reserved.
\end{abstract}

Manuscript submitted November 2, 2006; revised manuscript received January 19, 2007. Available electronically March 26, 2007

Silicon has been projected as a new negative electrode material for lithium secondary batteries. Even if it possesses a higher theoretical specific capacity than that of graphite, ${ }^{1-3}$ its practical use is still delayed because of severe volume change during chargedischarge cycling. ${ }^{4-9}$ Several approaches have been made to solve this problem, for instance, by using an elastomeric binder, ${ }^{10}$ or by composite formation with conductive materials such as carbon nanotubes (CNTs). ${ }^{11-13}$

The preparation of silicon carbon nanotube $(\mathrm{Si} / \mathrm{CNT})$ composite materials has been reported in the literature including our own. ${ }^{11-13}$ In these preparations, a core/shell type $\mathrm{Si} / \mathrm{CNT}$ composite was prepared, where Ni catalyst that was loaded on the Si surface by electroless deposition was used for chemical vapor deposition of CNTs. ${ }^{13-16}$ A better anodic performance observed with the Si/CNT composite electrodes as compared to bare $\mathrm{Si}$ has been ascribed to the conductive buffering role of the CNT layer. That is, it has been proposed that the void space and flexible nature of the CNTs allow a volume expansion of $\mathrm{Si}$ core without severe electrode swelling. ${ }^{13}$

In this work, we tried to prepare a Si/CNT composite material by using commercial CNTs as the starting material. This preparation seems much simpler than those reported earlier because the processes for catalyst loading and CNT growth are absent. The major obstacle was, however, a difficulty in disentangling the highly agglomerated CNTs. After a literature survey and many trials, this problem has been solved to have Si-embedded CNT powders, which was possible by dispersing $\mathrm{Si}$ and CNT powder in poly(vinyl chloride) (PVC)-dissolved tetrahydrofuran (THF) solution. The PVC was carbonized at the final step. As will be seen, the CNTs carry a void space that expectedly plays a buffering role against the volume expansion of Si matrix. An electrochemical dilatometer was utilized to trace the macroscopic electrode expansion/contraction with charge-discharge cycling. ${ }^{17-20}$ The cycle performance of Si-C/NT electrodes has been correlated to the electrode swelling, which is in turn deeply associated with the buffering action of void spaces in the $\mathrm{Si}-\mathrm{C} / \mathrm{NT}$ powders.

\section{Experimental}

For the preparation of $\mathrm{Si}-\mathrm{CNT}$ powders, Si powder (Aldrich Chemical Co., $20 \mu \mathrm{m}$ average diameter) and CNT powder (Iljin Nanotech. Co., 10-20 nm diam, 10-20 $\mu \mathrm{m}$ length) were dispersed in a THF solution, wherein PVC $(\mathrm{Mw}=\sim 80,000)$ is dissolved. For uniform mixing and dispersion, the mixture was treated in a sonication bath for $30 \mathrm{~min}$, which was followed by drying in a rotary evaporator. The Si/PVC/CNT composite powders were then heattreated at $900^{\circ} \mathrm{C}$, for $2 \mathrm{~h}$ under Ar atmosphere to carbonize the PVC component. The as-purchased $\mathrm{Si}$ powder was ballmilled to obtain

\footnotetext{
* Electrochemical Society Active Member

${ }^{\text {z }}$ E-mail: seungoh@snu.ac.kr
}

smaller Si particles $(0.5 \mu \mathrm{m}$ average diameter), from which another Si-embedded CNT powder ( $\mathrm{mSi}-\mathrm{C} / \mathrm{NT} 35)$ was prepared. In this notation, $\mathrm{mSi}$, C, and NT denote the milled Si powder, PVC-derived carbon, and carbon nanotubes, respectively. The number indicates the wt $\%$ of CNTs in the sample.

Microscopic investigations were carried out with a transmission electron microscope (TEM, JEOL JEM 2000 EXII) and a scanning electron microscope (SEM, JEOL JSM-6700F). Carbon content in the $\mathrm{Si}-\mathrm{C} / \mathrm{NT}$ powders was determined from the thermogravimetric analysis (TGA) profiles that were recorded from room temperature to 1000 at $10 \mathrm{~min}^{-1}$ in air. To determine the pore volume in $\mathrm{Si}-\mathrm{C} / \mathrm{NT}$ powders, Brunauer-Emmett-Teller (BET) surface area was measured from the nitrogen adsorption isotherms.

To prepare the negative electrodes, a mixture of Si-C/NT powder, Super P (as a carbon additive for conductivity enhancement), and polyvinylidene fluoride ( $\mathrm{PVdF}$, as a polymeric binder, 75:5:25 in weight ratio) was dispersed in $N$-methylpyrrolidone and homogenized. The resulting slurry was spread on a piece of copper foil (thickness $10 \mu \mathrm{m}$, apparent area $1 \mathrm{~cm}^{2}$ ) and dried in vacuum at $120^{\circ} \mathrm{C}$ for $12 \mathrm{~h}$. The electrode plate was then pressed to enhance the interparticle contact and to ensure a better adhesion to the current collector. A beaker-type three-electrode cell was employed to assess the electrochemical performance of the samples. Lithium foils $(\mathrm{Cy}$ prus Co.) were used as the counter and reference electrode, respectively, and $1.0 \mathrm{M} \mathrm{LiClO}_{4}$ dissolved in a mixture of ethylene carbonate (EC) and diethyl carbonate (DEC) (1:1 volume ratio) was used as the electrolyte. Galvanostatic charge-discharge cycling was made at a current density of $200 \mathrm{~mA} \mathrm{~g}^{-1}$ in the voltage range of $0.0-2.0 \mathrm{~V}$ (vs Li/ $/ \mathrm{Li}^{+}$) with a WBC-3000 battery cycler (Xeno Co.). The thickness change of electrodes was measured using a homemade electrochemical dilatometer, of which the schematic drawing was provided in previous reports. $18-20$

\section{Results and Discussion}

Figure 1a shows the SEM image of pristine CNT powder, where it is seen that the CNT powder carries a somewhat rounded shape $<20 \mu \mathrm{m}$ in size. The magnified view clearly shows that the fiberlike CNTs are highly entangled, giving rise to a large void space (Fig. 1c). A disentanglement and dispersion of CNTs in solution is known to be difficult, as CNTs have a strong tendency to agglomerate, bundle together, and entangle. ${ }^{21-24}$ Several CNT-polymer composites have been prepared, for instance, CNT/poly(vinyl alcohol) $(\mathrm{PVA})^{25}$ and CNT/polystyrene (PS) ${ }^{22}$ which evidences that CNTs can be disentangled to some degree when dispersed in solution with polymers. In these preparations, the polymers are known to either thread onto or wrap around the surfaces of CNTs. ${ }^{26-28}$ As a result of polymer wrapping, CNTs can be solubilized to some degree as van der Waals interactions that cause CNTs to aggregate into bundles are weakened. In this work, PVC was chosen as the dispersion agent because it does not contain oxygen atoms. Note that the Si/CNT 

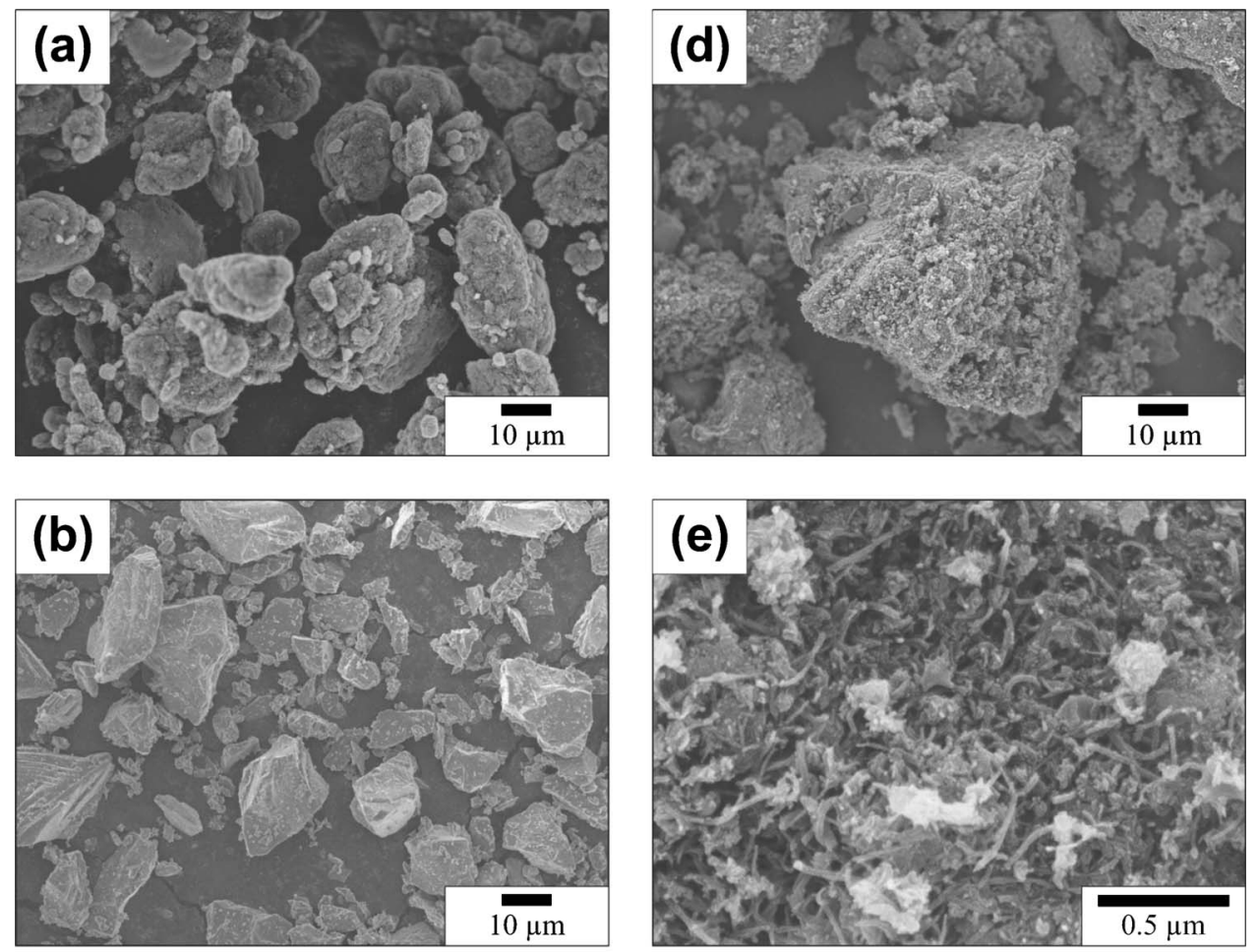

Figure 1. The SEM image of the samples: (a) pristine CNT powder, (b) pristine $\mathrm{Si}$ powder, (c) magnified view of pristine CNT powder, (d) Si-embedded CNT pow$\operatorname{der}(\mathrm{Si}-\mathrm{C} / \mathrm{NT}-30)$, and (e) magnified view of $\mathrm{Si}-\mathrm{C} / \mathrm{NT}-30$ powder. The TEM image of $\mathrm{mSi}-\mathrm{C} / \mathrm{NT} 35$ powder is shown in (f), where the misty image is supposed to come from the PVC-derived carbon.
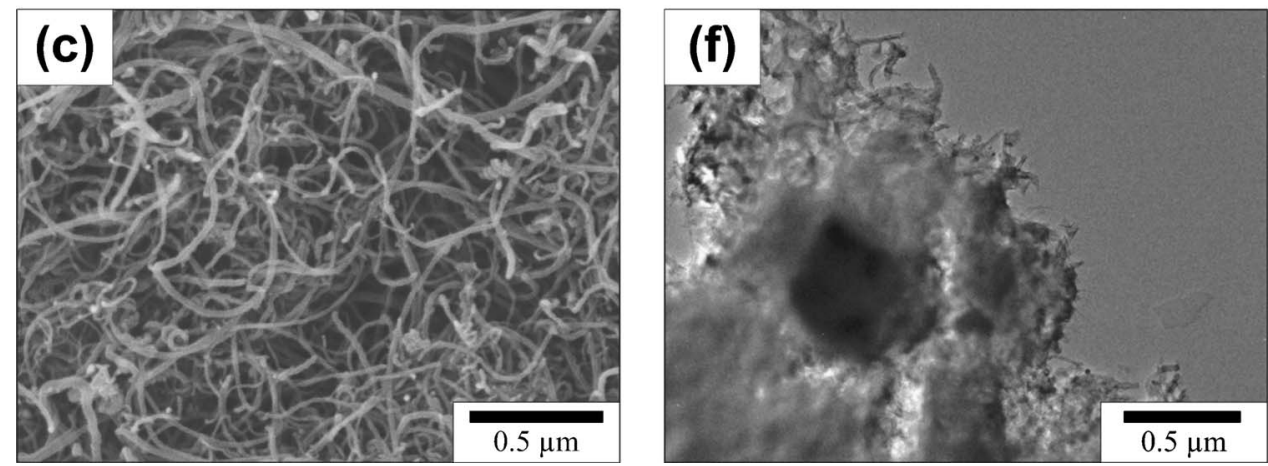

composites in this preparation should be heat-treated for the carbonization of polymeric component, where $\mathrm{Si}$ can be oxidized if the polymers contain oxygen atoms. The PVC-derived carbon can also provide an electric conduction pathway between $\mathrm{Si}$ and the CNTs.

The scanning electron microscopy (SEM) image of Si-C/NT powder is displayed in Fig. 1d, where the surface-roughened particles of a few tens of micrometers in size appear. Evidently, the size is much bigger than those of CNTs (Fig. 1a) and Si particles (Fig. 1b). The absence of irregular-shaped Si particles and the formation of much larger particles in Fig. 1d reflect that the Si particles are embedded inside the CNTs, which were disentangled by the polymeric dispersion agent. The magnified view further indicates that the outside layer is composed of the CNTs and PVC-derived carbon (Fig. 1e). The CNTs still carry void spaces but in a reduced amount due to the incorporation of PVC-derived carbon. Figure 1f shows the TEM image of $\mathrm{mSi}-\mathrm{C} / \mathrm{NT} 35$ powder that was prepared with $0.5 \mu \mathrm{m}$ sized $\mathrm{Si}$ particles. It is seen that the $\mathrm{Si}$ particles are well dispersed in the CNTs matrix, and that the PVC-derived carbon is incorporated into the CNTs matrix to provide an electric conduction network between $\mathrm{Si}$ particles and CNTs. ${ }^{29,30}$

Table I lists the composition of Si, PVC-derived carbon, and CNTs in each sample, which were obtained from the TGA data. In this preparation, the amount of PVC-derived carbon was deliberately controlled by trial and error to reach the targeted value (30-65 wt \%) by adjusting the PVC addition in the preparation step, while the composition of Si (35 wt \%) and CNTs (0-35 wt \%) was predetermined. The TGA result exhibited that the major weight loss takes place at $500-650^{\circ} \mathrm{C}$ due to the oxidation of CNTs and PVCderived carbon. Weight percent of the latter was calculated on the basis of predetermined CNT content. Table I also lists the BarrettJoyner-Halenda $(\mathrm{BJH})$ pore volume derived from the $\mathrm{N}_{2}$ gas adsorption isotherm measured at $77 \mathrm{~K}$. The $\mathrm{Si}-\mathrm{C}$ sample that was

Table I. The composition, pore volume, and 1st charging capacity of the samples.

\begin{tabular}{|c|c|c|c|c|c|}
\hline & & \multicolumn{2}{|c|}{ Composition (wt \%) } & \multirow[b]{2}{*}{$\begin{array}{c}\text { Pore } \\
\text { volume } \\
\left(\mathrm{cm}^{3} \mathrm{~g}^{-1}\right)\end{array}$} & \multirow[b]{2}{*}{$\begin{array}{c}\text { 1st charging } \\
\text { capacity } \\
\left(\mathrm{mAh} \mathrm{g}^{-1}\right)\end{array}$} \\
\hline & $\mathrm{Si}$ & $\begin{array}{l}\text { PVC-derived } \\
\text { carbon }\end{array}$ & CNTs & & \\
\hline $\mathrm{Si}-\mathrm{C}$ & 35 & 65 & 0 & 0.02 & 1694 \\
\hline $\mathrm{Si}-\mathrm{C} / \mathrm{NT} 25$ & 35 & 40 & 25 & 0.08 & 1609 \\
\hline $\mathrm{Si}-\mathrm{C} / \mathrm{NT} 30$ & 35 & 35 & 30 & 0.20 & 1800 \\
\hline $\mathrm{Si}-\mathrm{C} / \mathrm{NT} 35$ & 35 & 30 & 35 & 0.28 & 1920 \\
\hline mSi-C/NT35 & 36 & 30 & 34 & 0.29 & 1971 \\
\hline
\end{tabular}

${ }^{\mathrm{a}} \mathrm{BJH}$ pore volume derived from nitrogen adsorption isotherms.

${ }^{\mathrm{b}}$ Obtained from the charge-discharge voltage profiles in Fig. 2. 
prepared by heat-treatment of $\mathrm{Si} / \mathrm{PVC}$ mixture shows a negligible pore volume, indicative of a very low porosity in the PVC-derived carbon. It was found in separate measurements that the pore volume of CNTs and PVC-derived carbon is 0.69 and $0.01 \mathrm{~cm}^{3} \mathrm{~g}^{-1}$, respectively. In the series of $\mathrm{Si}-\mathrm{C} / \mathrm{NT}$ samples, the pore volume increases progressively with an increase in the CNT content. Given that the PVC-derived carbon is nonporous, the void spaces must be located inside the CNTs matrix after some being occupied by the Si particles and PVC-derived carbon.

Figure 2 displays the height change of electrodes (dotted lines) that was obtained by the electrochemical dilatometry experiments. Overall, all the electrodes show a swelling in charging and contraction upon discharging. The conversion point from swelling to contraction is well matched with the charge-discharge switching (solid lines). The maximum electrode swelling in the first charging is compared for the electrodes in Fig. 2f. The CNT-free Si-C electrode shows $277 \%$ expansion in the normal direction, but the degree of expansion becomes smaller with an increase in CNT content. Before we draw a conclusion that the inverse relationship between electrode swelling and CNT content results from the buffering action of CNTs, one point should be clarified as to whether the volume expansion of the Si matrix is comparable for all the electrodes. It this condition is not met either by different $\mathrm{Si}$ loadings or by different degrees of lithiation, the discussion on buffering action of CNTs is meaningless. Along this line, the first charging capacity is listed in the last column in Table I. The observed values are very close to the theoretical ones, which were calculated with an assumption that the three components are fully charged with their own capacity. For instance, the Si-C/NT30 electrode delivers $1800 \mathrm{mAh} \mathrm{g}^{-1}$ in the first charging, which is in a good agreement with the theoretical value $\left(1810 \mathrm{mAh} \mathrm{g}^{-1}\right)$. In this calculation, the charging capacity of Si was assumed to be $3580 \mathrm{mAh} \mathrm{g}^{-1}$, and those for CNTs and PVCderived carbon 956 and $285 \mathrm{mAh} \mathrm{g}^{-1}$, respectively. ${ }^{31}$ The latter two values were obtained by a separate measurement made with the pure CNTs and PVC-derived carbon. An agreement between the observed and calculated capacity ascertains that the Si component, loaded with the same amount (35 wt \%) for each electrode, is fully lithiated to cause the same amount of volume expansion for the electrodes. Note that the volume expansion of carbons, therefore, CNTs and PVC-derived carbon, is much smaller even if they are fully charged. ${ }^{32}$ Now, because the volume expansion of Si is largely the same for the electrodes, the inverse relation between the electrode swelling and CNT loading can be rationalized on the basis of a buffering action of the CNTs.

The cycle performance of $\mathrm{Si}-\mathrm{C} / \mathrm{NT}$ electrodes is provided in Fig. 3. The $\mathrm{Si}-\mathrm{C}$ electrode shows a rapid capacity fading within a few cycles, thus omitted. The $\mathrm{Si}-\mathrm{C} / \mathrm{NT}$ electrodes deliver a first discharge capacity amounting to $1100-1200 \mathrm{mAh} \mathrm{g}^{-1}$. In order to estimate those delivered by the $\mathrm{Si}$ component itself, a simple calculation was made. It was found in separate measurements that the first discharging capacity of PVC-derived carbon and CNTs is 235 and $194 \mathrm{mAh} \mathrm{g}^{-1}$, respectively, after being charged to 285 and $956 \mathrm{mAh} \mathrm{g}^{-1}$. This implies that the major portion of discharge capacity comes from the $\mathrm{Si}$ component. For instance, the first discharge capacity delivered by $\mathrm{Si}, \mathrm{PVC}-$ derived carbon, and CNTs in $\mathrm{Si}-\mathrm{C} / \mathrm{NT} 35$ electrode is calculated to be $998,71,68 \mathrm{mAh} \mathrm{g}^{-1}$, respectively. This calculation ensures that the discharge capacity values in Fig. 3 are directly associated with those for Si component rather than the CNTs or PVC carbon. It is now sure that the cycle performance of $\mathrm{Si}$ component becomes better with an increase in the CNT loading.

Figure 4 schematically illustrates how the CNTs play the buffering role against volume expansion of the $\mathrm{Si}$ matrix. Conventional $\mathrm{Si}$ electrodes are prepared by coating a slurry mixture of Si powder, carbon black, and polymeric binder on copper foil. During charging (alloying with lithium), the composite electrode expands severely to generate cracks in the conducting matrix. In the forthcoming discharging, Si contracts to cause a breakdown of the electric conduction network between the $\mathrm{Si}$ and the carbon matrix (Fig. 4a). In the

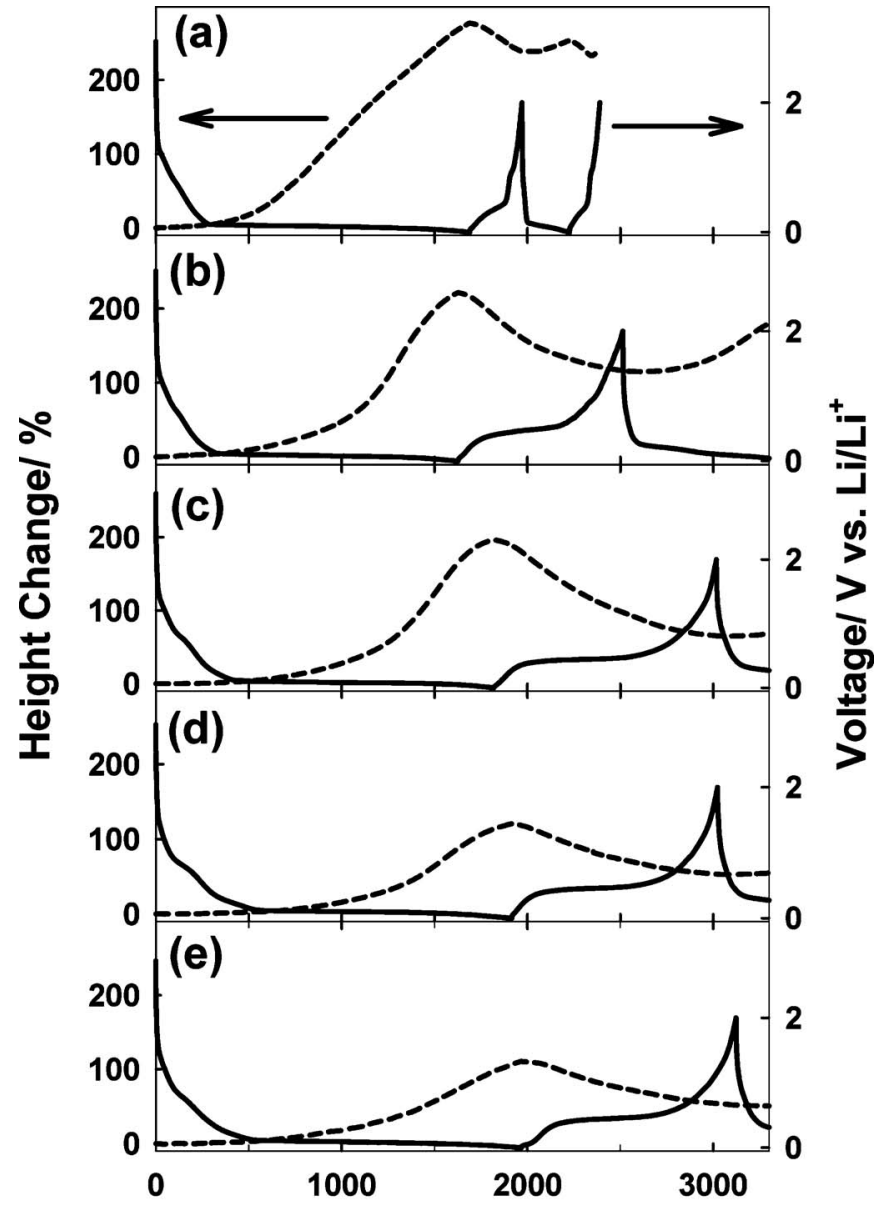

Specific capacity/ mAh $\mathrm{g}^{-1}$

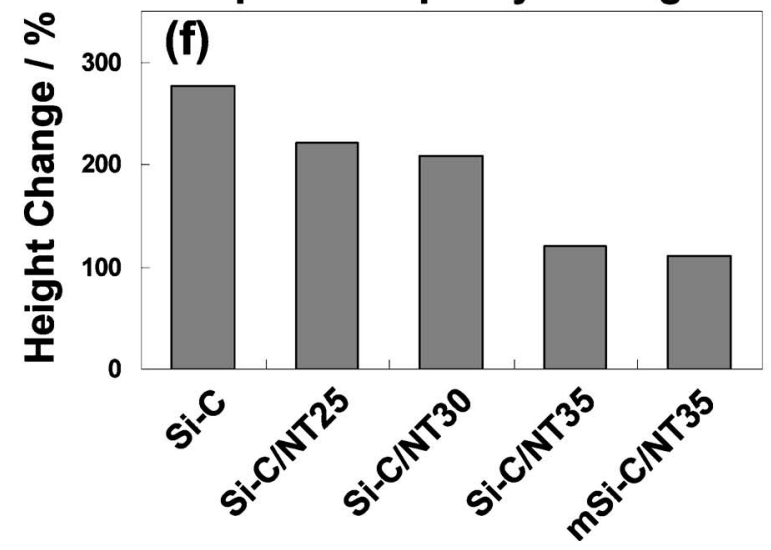

Figure 2. The height change of electrodes that was traced with an electrochemical dilatometer with cycling: (a) $\mathrm{Si}-\mathrm{C}$, (b) $\mathrm{Si}-\mathrm{C} / \mathrm{NT} 25$, (c) Si-C/NT30, (d) Si-C/NT35, (e) mSi-C/NT35, and (f) the maximum electrode swelling in the first charging. Note that the electrode swelling becomes smaller with an increase in the CNT content.

case of the $\mathrm{Si}-\mathrm{C} / \mathrm{NT}$ electrodes, however, electrode swelling may not be so severe because CNTs play a buffering role during charging. Even if the Si particles are contracted in the forthcoming discharging, the flexible CNTs can still provide an electronic pathway by being stretched (Fig. 4b).

Finally, the better cycle performance observed with mSi-C/NT35 electrode (Fig. 3) can be ascribed to a larger contact area between $\mathrm{Si}$ and CNTs. It is likely that the electric conduction network is better made when smaller Si particles are loaded. 


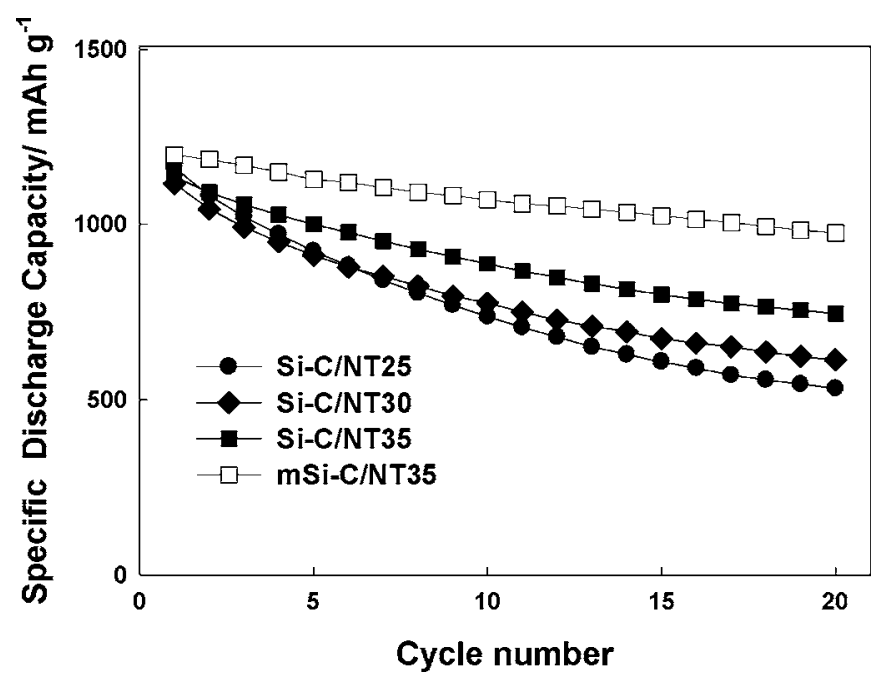

Figure 3. Cycle performance of a series of $\mathrm{Si}-\mathrm{C} / \mathrm{NT}$ electrodes. The specific discharge capacity calculated on the basis of total electrode weight is compared for the electrodes. Note that a better cycle performance is observed with the electrodes containing a larger amount of CNTs.

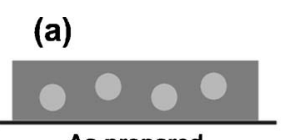

As prepared

(b)

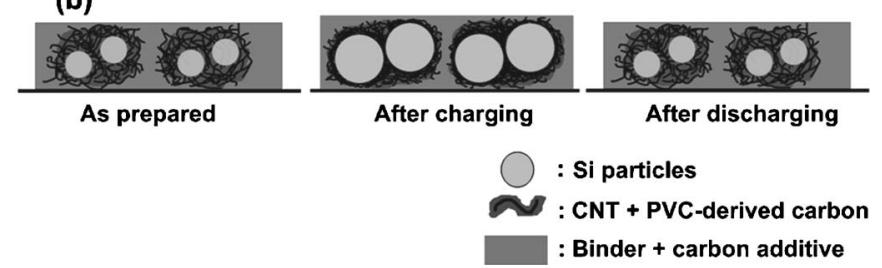

Figure 4. Schematic illustration of the failure mode encountered in Si negative electrode: (a) normal Si powder electrode and (b) Si-embedded CNT electrode. It is shown that the breakdown of the electric conduction network is severe in (a) but is greatly alleviated in (b) due to the buffering action of CNTs.

\section{Conclusion}

Si-embedded CNT powders were successfully prepared by using a commercial CNT powder as the starting material. This preparation is much simpler than those reported in the previous literature, in that the catalyst loading and CNT growth steps are eliminated. A disentanglement and dispersion of CNTs in solution was possible by using PVC as a dispersing agent. The electrode swelling was compared for the electrodes by an electrochemical dilatometry experiment, where it was found that the electrode swelling becomes less significant with an increase in the CNT content. Due to large void spaces in CNTs and their mechanical flexibility, the electrode swelling is greatly reduced and the electric conduction network is well maintained, which eventually gives a much improved cycle performance.

\section{Acknowledgments}

This work was supported by KOSEF via the Research Center for Energy Conversion and Storage, and by the Division of Advanced Batteries in the NGE Program (project no. 10016439). We are grateful to Dr. M. Hahn (Paul Scherrer Institute, Switzerland) for his assistance in fabricating the electrochemical dilatometer.

Seoul National University assisted in meeting the publication costs of this article.

\section{References}

1. J. O. Besenhard, J. Yang, and M. Winter, J. Power Sources, 68, 87 (1997).

2. M. Winter and J. O. Besenhard, Electrochim. Acta, 45, 31 (1999).

3. M. Winter, J. O. Besenhard, M. E. Spahr, and P. Novak, Adv. Mater. (Weinheim, Ger.), 10, 725 (1998).

4. T. D. Hatchard and J. R. Dahn, J. Electrochem. Soc., 151, A838 (2004).

5. L. K. Beaulieu, K. W. Eberman, R. L. Turner, L. J. Krause, and J. R. Dahn, Electrochem. Solid-State Lett., 4, A137 (2001).

6. M. Yoshio, H. Wang, K. Fukuda, T. Umeno, N. Dimov, and Z. Ogumi, J. Electrochem. Soc., 149, A1598 (2002).

7. N. Dimov, K. Fukuda, T. Umeno, S. Kugino, and M. Yoshio, J. Power Sources, 147, 227 (2005).

8. J. W. Kim, J. H. Ryu, K. T. Lee, and S. M. Oh, J. Power Sources, 114, 88 (2003)

9. J. H. Ryu, J. W. Kim, Y. E. Sung, and S. M. Oh, Electrochem. Solid-State Lett., 7 , A306 (2004)

10. W. R. Liu, M. H. Yang, H. C. Wu, S. M. Chiao, and N. L. Wu, Electrochem Solid-State Lett., 8, A100 (2005).

11. Y. Liu, T. Matsumura, N. Imanishi, A. Hirano, T. Ichikawa, and Y. Takeda, Elec trochem. Solid-State Lett., 8, A599 (2005).

12. Z. P. Guo, E. Milin, J. Z. Wang, J. Chen, and H. K. Liu, J. Electrochem. Soc., 152, A2211 (2005).

13. T. Kim, Y. H. Mo, K. S. Nahm, and S. M. Oh, J. Power Sources, In press.

14. V. I. Merkulov, D. H. Lowndes, Y. Y. Wei, and G. Eres, Appl. Phys. Lett., 76, 3555 (2000).

15. Y. Li, W. Kim, Y. Zhang, M. Rolandi, D. Wang, and H. Dai, J. Phys. Chem. B, 105, 11424 (2001).

16. C. L. Cheung, A. Kurtz, H. Park, and C. M. Lieber, J. Phys. Chem. B, 106, 2429 (2002).

17. M. Holzapfel, H. Buqa, L. J. Hardwick, M. Hahn, A. Wursig, W. Scheifele, P. Novak, R. Kötz, C. Veit, and F. M. Petrat, Electrochim. Acta, 52, 973 (2006).

18. M. Hahn, O. Barbieri, R. Gallay, and R. Kötz, Carbon, 44, 2523 (2006).

19. M. Hahn, O. Barbieri, F. P. Campana, R. Kötz, and R. Gallay, Appl. Phys. A, 82, 633 (2006).

20. M. Winter, G. H. Wrodnig, J. O. Besenhard, W. Biberacher, and P. Novak, $J$ Electrochem. Soc., 147, 2427 (2000).

21. X. L. Xie, Y. W. Mai, and X. P. Zhou, Mater. Sci. Eng., R., 49, 89 (2005).

22. D. Qian, E. C. Dickey, R. Andrews, and T. Rantell, Appl. Phys. Lett., 76, 2868 (2000)

23. J. P. Salvetat, A. D. Briggs, J. M. Bonard, R. R. Bacsa, A. J. Kulik, T. Stockli, N. A. Burnham, and L. Forro, Phys. Rev. Lett., 82, 944 (1999).

24. S. M. O'Flaherty, R. Murphy, S. V. Hold, M. Cadek, J. N. Coleman, and W. J. Blau, J. Phys. Chem. B, 107, 958 (2003)

25. M. Cadek, J. N. Coleman, K. P. Ryan, V. Nicolosi, G. Bister, A. Fonseca, J. B. Nagy, K. Szostak, F. Beguin, and W. J. Blau, Nano Lett., 4, 353 (2004).

26. S. Li, Y. Quin, S. Jiahua, Z. X. Guo, Y. Li, and K. Zhu, Chem. Mater, 17, 130 (2005).

27. J. Chen, H. Liu, A. W. Weimer, M. D. Halls, D. H. Waldeck, and G. C. Walker, J. Am. Chem. Soc., 124, 9034 (2002).

28. A. Star, J. F. Stoddart, D. Steuerman, M. Diehl, A. Boukai, E. W. Wong, X. Yang, S. W. Chung, H. Choi, and J. R. Heath, Angew. Chem. Int. Ed., 40, 1721 (2001).

29. H. Y. Lee, J. K. Baek. S. W. Jang, S. M. Lee, S. T. Hong, K. Y. Lee, and M. H. Kim, J. Power Sources, 101, 206 (2001).

30. D. Dollimore and G. R. Heal, Carbon, 5, 65 (1967)

31. M. N. Obrovac and L. Christensen, Electrochem. Solid-State Lett., 7, A93 (2004).

32. T. Ohzuku, Y. Iwakoshi, and K. Sawai, J. Electrochem. Soc., 140, 2490 (1993). 